\title{
Da Fonética à Fonologia: conquistas teóricas e metodológicas
}

\author{
Lucas Santos SILVA (1) \\ Universidade Federal de Sergipe (UFS) \\ Victor Renê Andrade SOUZA 『 \\ Universidade Federal de Sergipe (UFS)
}

○

OPEN ACCESS

EDITADO POR

Raquel Freitag

AVALIADO POR

Thaïs Cristófaro Silva

SOBRE OS AUTORES

Lucas Santos Silva Contribuiu com Victor Renê

Andrade Souza. Papéis: investigação, escrita - análise e edição.

Victor Renê Andrade Souza Contribuiu com Lucas Santos Silva. Papéis: conceptualização, supervisão, escrita - análise e edição.

DATAS

Recebido: 25/07/2020 Aceito: 01/09/2020 Publicado: 03/09/2020

COMO CITAR Silva, L. S.; Souza, V. R. A. (2020). Da Fonética à Fonologia: conquistas teóricas e metodológicas. Revista da Abralin, v. 19,

n. 2, p. 1-6, 2020.
RESUMO

Neste texto, apresentamos uma resenha da conferência Fonologia: conquistas e desafios proferida pela Professora Doutora Thaïs Cristófaro Silva (FALE-UFMG) e moderada pelo Professor Doutor José Sueli Magalhães (UFMG) no dia 16 de julho de 2020, integrando a programação do evento Abralin Ao Vivo - Linguists Online. Cristófaro-Silva explana acerca das conquistas, dos avanços e dos desafios dos últimos anos na Fonologia. A conferencista i) apresenta um panorama das contribuições metodológicas e teóricas da Fonética aos estudos de Fonologia, considerando as peculiaridades referentes aos respectivos campos de estudo; ii) considera fenômenos fonológicos emergentes no Português Brasileiro, a exemplo da nasalização e da palatalização; e iii) descreve as principais conquistas da Fonologia no Brasil, chamando atenção para a diversidade plurilinguística existente no país e o compromisso social dos cidadãos em conhecer esta realidade.

\section{ABSTRACT}

In this text, we present a review of the lecture Phonology: accomplishments and challenges delivered by Professor and Doctor Thaís Cristófaro Silva (FALE-UFMG) and mediated by the Professor and Doctor. José Sueli Magalhães (UFMG) on July $16^{\text {th }}, 2020$, as part of the program of the Abralin Ao Vivo - Linguists Online event. Cristófaro-Silva explains the accomplishments, advances, and challenges of the past years in Phonology. The lecturer i) presents an overview of the methodological and theoretical 


\section{REVISTA DA ABRALIN}

contributions from Phonetics to Phonology studies, considering the peculiarities referent to their respective fields of study; ii) considers the emerging phonological phenomena in Brazilian Portuguese, such as the nasalization and palatalization; and iii) describes the main accomplishments of Phonology in Brazil, drawing attention to the plurilinguistic diversity existent in the country and citizens' social commitment to know this reality.

PALAVRAS-CHAVE

Fonética. Fonologia. Conquistas metodológicas.

KEYWORDS

Phonetics. Phonology. Methodological accomplishments.

Uma das capacidades inatas ao ser humano é a capacidade da evolução. O homem é, por natureza, criativo e inovador. Inovamos e evoluímos sempre. Esses avanços trazem ganhos para toda humanidade e para diversas áreas do conhecimento científico. Sendo ciência, a Linguística também evoluiu muito, desde os neogramáticos aos estudos experimentais de processamento linguístico, com a disposição de novas teorias e metodologias.

As conquistas e os avanços dos últimos anos na Fonologia, explanadas pela Professora Doutora Thaïs Cristófaro Silva (FALE-UFMG) no evento Abralin ao Vivo - Linguists Online, são discutidas neste texto. A conferência Fonologia: conquistas e desafios, ocorrida no dia 16 de julho de 2020, foi mediada pelo Professor Doutor José Sueli Magalhães (UFMG).

Thaïs Cristófaro Silva é professora voluntária do Programa de Pós-Graduação em Estudos Linguísticos da Universidade Federal de Minas Gerais. É uma exímia profissional e referência nos estudos de Fonética e Fonologia do Português Brasileiro (PB). Além disso, possui uma vasta publicação de artigos e livros, dentre os quais citamos: Fonética e Fonologia do Português - Roteiro de Estudos e Guia de Exercícios (1999); Exercícios de Fonética e Fonologia (2003); e, mais recente, Fonética Acústica: os sons do português brasileiro (2019), os quais compõem a bibliografia de muitos cursos de Letras em todo o Brasil.

Na contextualização de sua fala, Cristófaro-Silva salienta a importância dos avanços da Fonética e a incorporação de outros aspectos que, geralmente, ficavam à margem dos estudos dos sons, a exemplo da relação entre Linguagem e Cérebro, numa perspectiva cognitivista. Esta progressão científica contribuiu diretamente para as reflexões da Fonologia enquanto área de conhecimento.

A autora exemplifica estes ganhos com o livro Articulatory phonetics (2013), de Bryan Gick, Ian Wilson e Donald Derrick, que traz reflexões sobre articulação dos sons e produção da fala por um viés anatômico, começando pelo cérebro, seguindo pelo sistema nervoso periférico e só então terminando com o movimento muscular. Este diálogo, para além de descrições puramente articulatórias, faz com que a ciência 


\section{REVISTA DA ABRALIN}

linguística progrida e fornece uma compreensão mais ampla do funcionamento da língua; não apenas sobre anatomia, mas sobre física e muitas coisas que ampliam esta área do conhecimento.

Cristófaro-Silva argumenta que a evolução da Fonética fez com que os foneticistas repensassem suas práticas, com a nova proposta de incorporar análise acústica e metodologias experimentais. Para autora, um desses avanços foi a criação do PRAAT, software gratuito que possibilita a análise acústica de dados de fala (BOERSMA; WEENINK, 2017), além de sintetizar e manipular desde os segmentos até a melodia dos sons da fala, criando figuras de alta qualidade como espectrogramas, oscilogramas, curvas de pitch e intensidade (FONSECA, 2009).

Se, com base nas experiências da própria pesquisadora, só era possível rodar um espectrograma da fala da noite para o dia, hoje, dispomos de novas tecnologias e até mesmo de novas metodologias que automatizaram o processo. Houve outros avanços, além do PRAAT, nas análises como o uso de vídeo na captura da fala (FREITAG et al., 2020); analise ultrassonográfica, usada para avaliar imagens dos órgãos internos durante a produção da fala (GICK, 2002; VASSOLER; BERTI, 2015); análise com uso do magnetômetro (EMA- electromagnetic articulography), que utiliza dispositivos de campo magnético alternativo para aquisição de dados articulatórios (BAKEN; ORLIKOFF, 2000; MEIRELES, 2017); uso de Eletropalatografia, que fornece informações do contato da língua com o palato em tempo real (JESUS, 2012); estudo com Eletroglotografia, utilizado para investigação das funções vibratórias das pregas vocais (MOURÃO; BASSI; GAMA, 2011); dentre outras perspectivas metodológicas.

Percebe-se, então, a evolução na Fonética em direção à Fonética Experimental. Para CristófaroSilva, esse direcionamento, por consequência, impactou na compreensão da Fonologia. À medida que são aplicadas novas metodologias também são feitas novas perguntas.

Outro avanço mencionado pela autora diz respeito à elaboração de um aparato simbólico capaz de representar e transcrever características da produção dos sons de línguas naturais, como é o caso do Alfabeto Fonético Internacional (International Phonetic Alphabet - IPA), elaborado pela Associação Internacional de Fonética, baseado no Alfabeto Latino. Apesar de sua importância, segundo Cristófaro-Silva, as representações do IPA são violáveis por, geralmente, serem confundidas com representações do sistema de escrita e representações fonológicas. Essa confusão é compreensível, uma vez as evidências mostram que as pessoas armazenam material linguístico com um código auditivo e motor-sensorial rico e detalhado que tende a ser único para cada falante (PAUL, 2011).

Para apresentar as diferenças das representações em cada um dos sistemas, Cristófaro-Silva sistematizou o quadro abaixo:

\begin{tabular}{|l|l|l|}
\hline \multicolumn{1}{|c|}{ FONÉTICA } & \multicolumn{1}{c|}{ FONOLOGIA } & \multicolumn{1}{c|}{ ESCRITA } \\
\hline Nível dos fones & Nível dos fonemas & Nível das letras \\
\hline Nível concreto/físico & Nível abstrato & Nível ortográfico \\
\hline Processamento motor & Processamento cognitivo & Processo de Escrita \\
\hline Pronunciável & Não-pronunciável & Leitura \\
\hline Desempenho & Competência & Escrita \\
\hline Gradiente & Discreto & Convencional \\
\hline$[\ldots . .$.$] colchetes$ & $/ \ldots /$ barras transversais & Letras \\
\hline
\end{tabular}




\section{REVISTA DA ABRALIN}

Mas, apesar dessa consolidação e dos avanços simbólicos do IPA, as normas de transcrição não têm chegado efetivamente à sala aula por meio dos livros didáticos. Cristófaro-Silva discorre acerca de uma pesquisa realizada em 8 livros didáticos nos quais encontrou padrões distintos para as representações fonéticas e fonológicas, a saber: 1) dados apresentados SEM [colchetes] ou /barras transversais /; 2) dados somente com as /barras transversais/ indicadas; 3) representações fonéticas apresentadas entre /barras transversais/, no caso de dicionários; 4) lista-se as formas ortográficas e indica-se fonologicamente o(s) símbolo(s) correspondente(s); 5) combina-se ortografia e representação fonética.

Os níveis de descrição e representações já consolidados são importantes e não são usados nos livros didáticos. Isso acontece, de acordo com autora, porque existe uma simbiose entre a Fonética e a Fonologia, um problema não resolvido e que requer muita atenção pela confusão que pode ser gerada. Para tanto, Cristófaro-Silva sugere a leitura de Sounds, brain, and evolution: or ,why phonology is plural (2007), de April Mcmahon, segundo o qual o problema na distinção entre os dois domínios similares é parte da nossa confusão representacional. Enquanto a Fonética trabalha com empírico e simbólico, a Fonologia trabalha com o abstrato (MCMAHON, 2007).

A autora continua sua fala explanando acerca da evolução teórica e de terminologias aplicadas à Fonologia. Temos, como exemplos: Representação Fonológica; Representação Fonêmica; Representação Subjacente, do Gerativismo; Representação Lexical; Representação Mental, dos Modelos de Uso (BYBEE, 2001) e da Teoria da Otimalidade (PRINCE; SMOLENSKY; 1993); Representação Gestual; Input; e Exemplares, do Modelo de Exemplares (JOHNSON, 1997; PIERREHUMBERT, 2001).

Essas mudanças teóricas e terminológicas são importantes para concebermos e percebermos o quanto a área evoluiu. Como exemplo, a autora recorre a uma comparação entre a proposta tradicional da Fonologia e o Modelo de Exemplares, apresentado no quadro 2.

\begin{tabular}{|l|l|}
\hline FONOLOGIA TRADICONAL & MODELO DE EXEMPLARES \\
\hline Representação mental minimalista & Representação mental detalhada \\
\hline Separação entre fonética e fonologia & Inter-relação entre fonética e fonologia \\
\hline $\begin{array}{l}\text { Visão de fonologia como uma gramática formal, com a } \\
\text { utilização de abstração }\end{array}$ & $\begin{array}{l}\text { Efeitos de frequência armazenados na memória de } \\
\text { longa duração }\end{array}$ \\
\hline Julgamento fonotático categórico & Efeitos de gradientes nos julgamentos fonotáticos \\
\hline Léxico separado de gramática fonológica & Palavras como lócus da categorização \\
\hline
\end{tabular}

QUADRO 2 - Comparação entre proposta Fonológica tradicional e o Modelo de Exemplares Fonte: Oliveira-Guimarães (2004, p. 40).

Em se tratando da Gramática e da Língua enquanto um sistema complexo, uma representação única, proposta pela Fonologia Tradicional, cria uma série de problemas para lidar com a dinamicidade que é inerente ao próprio sistema. Por isso, faz-se necessário pensar em formas alternativas, como a Fonologia Experimental ou Fonologia de Laboratório, uma abordagem proposta incialmente por Pierrehumbert, Beckman e Ladd (2000), que "buscou fortalecer as bases cientificas da fonologia, por meio da utilização de dados empíricos, do aprimoramento metodológico, da modelagem explicita e da acumulação de resultados" (CANTONI, 2013, p. 85). 


\section{REVISTA DA ABRALIN}

Para evidenciar os avanços metodológicos, a autora traz à baila um panorama de fenômenos fonológicos do Português Brasileiro (PB) e cita o processo da nasalização, quando uma vogal é seguida de uma consoante nasal (CÂMARA JR., 2009[1970]). A autora argumenta que no PB a nasalização em finais de sílabas e palavras é um fenômeno emergente, como nos casos vamos > [v^m], Dona Maria $>$ [donmariə] e cano torto $>$ [k^ntoht $]$. De tal forma, Cristófaro-Silva discorre acerca do fenômeno da palatalização de /t/ e /d/ diante da semivogal /y/ e/ou seguidas da vogal alta /i/, vogal média /e/ átona em posição elevada [i], que podem acontecer em realizações como ['ti.rv] e ['t $t$ i.ro] . Em ambos os fenômenos, a análise acústica, por exemplo, pode demonstrar a diferença espectrográfica entre o sinal da fala e a sua variabilidade quando observadas as características físicas de diferentes falantes.

Por fim, a autora descreve as principais conquistas da Fonologia no Brasil e chama a atenção para a diversidade linguística existente no Brasil, com ênfase para as línguas minoritárias e descrição dos sistemas sonoros de línguas indígenas. Além disso, a conferencista destaca a qualificação profissional advinda da abertura de diversos programas de Pós-Graduação em Linguística, Laboratórios, Grupos de Pesquisas e eventos em Fonética e Fonologia em inúmeros estados brasileiros.

Apesar de todo esse avanço teórico e metodológico na Fonologia, precisamos continuar evoluindo e dar mais um passo. Dispomos de amadurecimento científico e tecnológico para pensarmos novas propostas metodológicas e novas perguntas às nossas pesquisas e descrições linguísticas. Um desses avanços, para Cristófaro-Silva, seria formalizar uma proposta de integração com as ciências cognitivas, como em outros países, o que pode aprofundar a nossa compreensão sobre a produção da linguagem humana. Avancemos, pois!

\section{REFERÊNCIAS}

BAKEN, Ronald J.; ORLIKOFF, Robert F. Clinical measurement of speech and voice. Cengage Learning, 2000.

BOERSMA, Paul; WEENINK, David. Praat: Doing phonetics by computer (Versão 6.0.33). 2017. Disponível em: http://www.praat.org/. Acesso em: 21 mai. 2020.

BYBEE, Joan. Phonology and Language Use. Cambridge: Cambridge University Press, 2001.

CÂMARA Jr., Joaquim Mattoso. Estrutura da língua portuguesa. Petrópolis: Vozes. $42^{\text {a }}$ ed, 2009 [1970].

CANTONI, Maria Mendes. O acento no português brasileiro: uma abordagem experimental. 2013. Tese (Doutorado em Linguística Teórica e Descritiva), Faculdade de Letras, Universidade Federal de Minas Gerais, 2013.

CRISTÓFARO-SILVA, Thais, et al. Fonética Acústica: os sons do português brasileiro. São Paulo: Contexto, 2019.

CRISTÓFARO-SILVA, Thais. Exercícios de Fonética e Fonologia. São Paulo: Contexto, 2003.

CRISTÓFARO-SILVA, Thais. Fonética e Fonologia do Português: roteiro de estudos e guia de exercícios. 10. ed. São Paulo: Contexto, 2015. 


\section{REVISTA DA ABRALIN}

FONOLOGIA: conquistas e desafios. Conferência apresentada por Thaïs Cristófaro Silva [s.l., s.n.], 2020. 1 vídeo (1h 47 min 45s). Publicado pelo canal da Associação Brasileira de Linguística. Disponível em: https://www.youtube.com/watch?reload=9\&v=4V6soidUjOw. Acesso em: 19 mai. 2020.

FONSECA, Aline Alves. Análise do Tutorial do programa de análises acústicas Praat. Revista Texto Livre: linguagem e tecnologia, Vol. 1, nº 2, 2009. Disponível em http://dx.doi.org/10.17851/1983-3652.2.1.13-16 . Acesso em 21 mai. 2020.

FREITAG, Raquel Meister Ko. et al. Pilot study of the relationship between the judgment of linguistic features and facial expressions. Cadernos de Linguística, v. 1, n. 2, p. 01-19, 14 Aug. 2020.

GICK, Bryan. The use of ultrasound for linguistic phonetic fieldwork. Journal of the International Phonetic Association, p. 113-121, 2002.

GICK, Bryan; WILSON, Ian; DERRICK, Donald. Articulatory phonetics. Wiley-Blackwell, 2013.

JESUS, Marisa de Souza Viana. Estudos eletropalatográficos na fala normal e alterada decorrente da fissura labiopalatina. 2012. Tese (Doutorado em Linguística Teórica e Descritiva), Faculdade de Letras, Universidade Federal de Minas Gerais, 2012.

JONHSON, Keith. Speech perception without speaker normalization. In: JOHNSON, Keith; MULLENNIX, John W. (Ed.). Talker variability in speech processing. Morgan Kaufmann Publishers Inc., 1997.

MCMAHON, April. Sounds, brain, and evolution: or, why phonology is plural. In: PENNINGTON, Martha (Ed.). Phonology in context. Palgrave Macmillan, London, 2007. p. 159-185.

MEIRELES, Alexsandro Rodrigues. O uso do magnetômetro (EMA) na análise de dados articulatórios da prosódia da fala. In: FREITAG, Raquel Meister Ko; LUCENTE, Luciana (orgs). Prosódia da fala: pesquisa e ensino. São Paulo: Blucher, 2017.

MOURÃO, Aline Mansueto; BASSI, Iara Barreto; GAMA, Ana Cristina Côrtes. Avaliação eletroglotográfica de mulheres disfônicas com lesão de massa. Revista CEFAC, v. 13, n. 6, p. 1073-1080, 2011.

OLIVEIRA-GUIMARÃES, Daniela Mara Lima. Variação nas seqüências de (sibilante +africada alveopalatal) no português de Belo Horizonte. 2004. Dissertação (Mestrado em Linguística) - Faculdade de Letras, UFMG, Belo Horizonte, 2004.

PIERREHUMBERT, Janet. Exemplar dynamics: Word frequency, lenition and contrast. In: BYBEE, J.; HOPPER, P. (Ed.) Frequency effects and the emergence of linguistic structure. Amsterdam: John Benjamins, 2001. p. 1-19.

PIERREHUMBERT, Janet; BECKMAN, Mary; LADD, Robert. Conceptual foundations of phonology as a laboratory science. In: BURTON-ROBERTS, Noel; CARR, Philip; DOCHERTY, Gerard (ed.). Phonological Knowledge: conceptual and empirical issues. Oxford: Oxford University Press, 2000. p. 273-303.

PORT, Robert. Phones and phonemes are conceptual blends, not cognitive letters. Proceedings of the Annual Meeting of the Cognitive Science Society, 33(33). 2011.

PRINCE, Alan; SMOLENSKY, Paul. Optimality Theory - Constraint Interaction in Generative Grammar. RuCCs Technical report 2, 1993.

VASSOLER, Aline Mara de Oliveira; BERTI, Larissa Cristina. Análise ultrassonográfica quantitativa da produção de encontros consonantais realizadas por crianças típicas e atípicas. In: Anais do XXIII Congresso Brasileiro e IX Congresso Internacional de Fonoaudiologia. São Paulo: SBFA, 2015. 